\title{
Estrategias y prácticas tradicionales amigables con la naturaleza en comunidades negras y Embera
}

\section{Traditional strategies and practices friendly with nature in black and Embera communities}

\section{Jairo Miguel Guerra Gutiérrez*}

\section{Resumen}

Las tradiciones de las comunidades afropacífico y Embera asentadas en el Pacifico tienen diferencias y elementos en común; a los Embera se les puede ubicar en una "matriz cultural compartida” en todo el Chocó Biogeográfico colombiano. Observaciones en diferentes escenarios, particularmente en comunidades asentadas en el golfo de Tribugá, constituyen una muestra importante de esta matriz que es una opción valiosa para reconocer elementos de identidad regional y base para planear la conservación de biodiversidad existente en los ecosistemas del área. Las investigaciones en el golfo de Tribugá involucran 7 comunidades, tres afropacífico (Joví, Termales y Partadó) y cuatro Embera dóbida (Yucal del río Panguí, Tandó y Nuqui del río Nuquí y Jagua del río Chorí), realizadas en el marco de la ejecución del proyecto "Incorporación de conocimientos tradicionales asociados a la agrobiodiversidad en los agroecosistemas colombianos". La metodología utilizada fue la etnografía implementada con instrumentos de observación participativa, acompañamiento a las comunidades en el establecimiento de parcelas de cultivos asociados, eventos de rescate de semillas nativas, documentación de conocimientos tradicionales y su valoración a través del impulso de estrategias de comunicación en las comunidades. Como resultado se identificaron dos estrategias asociadas con la cosmovisión del territorio y cinco prácticas asociadas con la agrobiodiversidady ecosistemas contiguos compartidas por comunidades indígenas Emberas y afrodescendientes con funciones de conservación de biodiversidad.

Palabras clave: Costumbres compartidas en el Pacífico, Identidad Pacífico, Prácticas culturales amigables con la naturaleza.
* Especialista en gestión agroambiental, Universidad Nacional, sede Medellín y Asesor de dirección, Instituto de Investigaciones Ambientales del Pacífico (IIAP), Chocó, Colombia. e-mail: iguerra2@iiap.org.co 


\section{Bioetnia Volumen 12, 2015}

\section{Abstract}

The traditions of the afropacifico and Embera communities living in the Pacific have differences and common elements, the latter can locate them in a "shared cultural matrix" throughout the Colombian Chocó biogeographic region. Observations in different settings, particularly in communities located in the Gulf of Tribugá, are an important example of this matrix is a valuable option to recognize elements of regional identity and basis for planning the conservation of biodiversity in ecosystems of the area. Research in the Gulfof Tribugá involve six communities, three afropacifico (Joví, Thermal, Partadó) and three Embera Dóbida (Yucal of Panguí River, Nuquí Arriba of Nuqui river and Bocas de Jagua of Chorí river), made under project implementation "incorporating traditional knowledge associated with agricultural biodiversity in agroecosystems Colombian". The methodology was from the accompanying communities in establishing plots cropping, rescue of native seeds, documentation of traditional knowledge and its assessment by promoting communication strategies in communities. As a result two strategies associated with the worldview of territory and five practices associated agrobiodiversity and shared by Embera indigenous and afro-descendant communities with biodiversity conservation features were identified adjacent ecosystems.

Keywords: Friendly cultural practices to nature Pacific identity, Shared customs in the peaceful.

\section{Introducción}

"Respaldos" y "encierros" son dos conceptos ligados con estrategias de relacionamiento entre la población afro y Embera respectivamente en el Chocó Biogeográfico; estas a su vez se constituyen prácticas tradicionales amigables con la naturale- za, las cuales presentan una gran importancia de análisis y documentación, dada su relevancia en el estudio de las dinámicas que han permitido la conservación del patrimonio cultural de la región, más aun cuando actualmente se hace urgente la búsqueda y réplica de estrategias que desde lo comunitario garanticen el éxito de preservación de los recursos naturales presentes en áreas de interés ambiental y sociocultural.

Desde esta perspectiva, el respaldo es la denominación de una de las áreas de uso en el ordenamiento del territorio ancestral de las familias afropacífico y en algunos casos adoptado por indígenas; esta área no tiene un polígono preciso, pero sí existe un concepto compuesto por un frente y un fondo. Ordinariamente el frente está delimitado por una quebrada o un río y unos mojones naturales también marcados por un cerro, una quebrada o árboles legendarios; en este frente ordinariamente se ubica la vivienda y cultivos de patio y el "respaldo" lo constituye un área con límites regularmente imaginarios en los lados y sin límites en el fondo o lo que alcance la vista. Este respaldo es de dominio familiar pero los recursos existentes en él son de uso comunitario, de tal manera que una persona perteneciente a la comunidad pero de una familia distinta a la que posee su dominio puede "proclamar" unas palmas que tienen "avistadas" y que necesita para coger unas goteras, igualmente puede proclamar un árbol que requiere para labrar una champa o canoa.

Por su parte, el "encierro" es una denominación dentro de la cosmología Embera, compartida por las diferentes etnias aborígenes asentadas en el Chocó Biogeográfico aplicada a una función de control de espíritus relacionados con especies de flora, fauna y en general con la vida. El encierro se relaciona con un concepto y áreas concretas de características particulares, cuya ubicación puede estar desde la orilla del mar hasta las elevaciones mayores a nivel de páramos; puede ser una ciénaga, un bosque homogéneo, una ladera, una planicie o una laguna en la parte alta de las 
Estrategias y prácticas tradicionales amigables. JM Guerra Gutiérrez

montañas; en los encierros, los sabios tradicionales, sacerdotes, chamanes o jaibanás, confinan a los espíritus o jais con el fin de convocarles al control del equilibrio en las condiciones de vida. Los espíritus o jais son "bia" buenos o "kachiruas" malos dependiendo de la percepción humana de ellos y unos como otros son controlados por los poderes del jaibaná particularmente para lograr el bienestar de la comunidad poniendo al alcance de su aprovechamiento la fauna de caza, las semillas o protegiendo a la comunidad de los males $o$ enfermedades.

Respaldos y encierros son conceptos que se relacionan con la facilidad del acceso a áreas con importante biodiversidad con alto valor de uso pero que por disposición de los humanos o de los espíritus se limita su aprovechamiento con la presencia en ellos de entes sagrados que amenazan a los humanos. Nusí, madreagua, dopacadde, madremonte, mohan, aribada, tulivieja, guangano, tunda o riviel entre otros, son entes que circundan los bosques y encantan las áreas de respaldo o encierro. En general, tanto respaldos como encierros están al servicio del bienestar humano y de los ecosistemas; en ellos se tipifican los sitios sagrados, saladeros, lamederos, criaderos de peces y fauna de caza, cotos semilleros de especies de alto valor de uso o ecológico.

Área de estudio. El proyecto "Incorporación del conocimiento tradicional asociado a los agroecosistemas colombianos", ejecutado en el sitio piloto del municipio de Nuquí, por el Instituto de Investigaciones Ambientales del Pacífico (IIAP), se desarrolló en el territorio del golfo de Tribugá, ubicado en la zona norte del litoral Pacífico chocoano, con las siguientes características: esta región se extiende desde la divisoria de aguas entre el río Chadó y la quebrada Caimanera, al norte de la población del Valle del municipio de Bahía Solano hasta la punta de Cabo Corriente en el corregimiento de Arusí, en el municipio de Nuquí, en el sur, abarcando toda el área comprendida entre la línea costera y la serranía del Baudó por zonas que corresponden a los resguardos indígenas del río Valle, alto Boroboro, pozamansa, Jurubirá-Chorí-Alto Baudó, ríos Nuquí y Panguí, el territorio colectivo de Los Riscales y algunos predios de propiedad privada.

En esta zona geográfica se encuentran asentadas las poblaciones de comunidades negras de El Valle, Jurubirá, Nuquí, Tribugá, Panguí, Coquí, Joví, Termales, Partadó y Arusí, ubicadas en las desembocaduras de los ríos al mar y en la parte media de los ríos se encuentran las comunidades indígenas de Jella en el río Joví, Yucal en el Panguí, Nuquí Arriba y Tandó en el Nuquí, Jagua, Puerto Indio y la Loma en el Chorí, Villanueva y Hoja Blanca en el Jurubirá, Pozamansa, El Brazo y Boroboro en el Valle.

\section{Métodos}

Para el levantamiento de información se aplicó la metodología etnográfica con elementos de investigación, acción y participación (IAP) desarrollada por el Fals Borda (1981), que parte de producir conocimiento que permite a sectores subalternos de la sociedad comprender su compleja realidad a fin de poderla transformar. Esta corriente de pensamiento estaba orientada por lo que hoy se conoce como el "paradigma emancipatorio", porque sus prácticas tienen una clara intencionalidad política al fortaleceren estos grupos sociales las capacidades que generaran cambios sociales. Esta metodología comprende la observación de la realidad para generar la reflexión sobre la práctica, la planificación y desarrollo de acciones para su mejoray la sistematización de las experiencias para la producción de conocimientos en el campo popular (Ortiz y Borjas, 2008).

Esta metodología se apoyó en el método de investigación etnográfico, es decir, que los grupos sociales de interés no se miraron como entes "objetos de estudio" sino grupos dinámicos reflexivos y participativos sujetos de acción. El trabajo de campo estuvo basado en la observación directa 


\section{Bioetnia Volumen 12, 2015}

de los fenómenos socioculturales.

Se trabajaron tres componentes desde los cuales se identificaron las estrategias y prácticas o costumbres tradicionales que hacen parte del cuerpo identitario o matriz cultural compartida: impulso de la agrobiodiversidad, documentación de tradiciones y valoración del conocimiento tradicional.

Se siguieron diferentes pasos para llegar a involucrar a las comunidades en los procesos de investigación. Lo primero fue identificar a las organizaciones comunitarias representativas de las comunidades asentadas en el golfo de Tribugá: El Consejo Comunitario General Los Riscales, propietario del título del territorio colectivo del área, el cual asocia nueve de consejos comunitarios locales y el Cabildo Mayor Indígena Zona Costa Pacífica (CAMIZCOP), que asocia los cabildos locales de las comunidades asentadas en los ríos Chorí, Nuquí y Panguí.

Estas organizaciones convocaron a sus comunidades filiales y con ellas se adelantó un proceso de socialización y concertación del proyecto en lo que se dedicaron largas jornadas de discusiones centradas particularmente en dos temas planteados por las comunidades, el destino de la información emanada de la investigación y los beneficios a obtener por parte de las familias involucradas. Al final de la concertación se definieron las comunidades a participar y la estructura de ejecución del proyecto diagnóstico, caracterización de prácticas tradicionales, identificación de especies que brindan bienes y servicios, descripción de procesos y manejos productivos de las actividades productivas realizadas por las familias indígenas Emberas y afrocolombianas del golfo de Tribugá (IIAP, 2012).

Comunidades negras seleccionadas: Partadó, Termales y Joví; los Riscales se seleccionaron con el criterio de participarles de los proyectos que llegan a la región; las otras ya estaban involucradas en otros proyectos. Comunidades Embera seleccionadas: Yucal del río Panguí, Nuquí Arriba del río Nuquí y Bocas de Jagua del río Chorí. Para la ejecución se acordó tener un animador comunitario local por comunidad, un enlace comunitario zonal que acompañara al equipo técnico tanto del orden regional contratado por el IIAP como el nacional contratado desde Bogotá. Se firmaron convenios entre el Programa de las Naciones Unidas para el Desarrollo (PNUD) con el IIAP y con las organizaciones comunitarias zonales Los Riscales y CAMIZCOP. El IIAP desarrolló los componentes impulso de la agrobiodiversidad, identificación de protección de los conocimientos tradicionales y valoración de los conocimientos tradicionales. Las organizaciones acompañaron a los técnicos y ejecutaron acciones de fortalecimiento institucional.

La participación comunitaria acordada para la ejecución del proyecto incluyó 10 familias por comunidad para el primer componente, las que establecieron parcelas con cultivos asociados y rescataron prácticas tradicionales; cinco reporteros o comunicadores comunitarios por comunidad para impulsar la estrategia de valoración de los conocimientos tradicionales y la promoción de grupos de custodios de tradiciones en cada comunidad entre los que se incluye la protección de los instrumentos musicales, las semillas nativas y la gastronomía, entre otros. El componente de protección de los conocimientos tradicionales involucró a todos los habitantes de las comunidades, generó grupos de custodios de semillas, de instrumentos musicales, de las pinturas corporales y de la gastronomía tradicional.

El proyecto se ejecutó teniendo como punto de partida la formulación de una línea de base de los conocimientos sobre los temas a tratar en la que se identificaron los sabios tradicionales, actores sociales de interés y redes de relaciones internas y externas; se describieron los procesos de comunicación, prácticas de cultivos y estado de las semillas y costumbres asociadas con estas. El equipo técnico zonal se integró por un antropólogo, un agroforestal, un comunicador social, un 
Estrategias y prácticas tradicionales amigables. JM Guerra Gutiérrez

enlace embera y un enlace negro. Este equipo fue presentado a las comunidades e iniciaron la ejecución con la realización de eventos individuales o colectivos para el levantamiento de información e implementación de las estrategias previstas.

Durante la investigación se realizaron charlas abiertas y semiestructuradas individuales y colectivas en las casas y en las visitas a los cultivos, observación participativa del proceso de montaje de parcelas o colinos, capacitaciones, actividades de comunicación y planeación de encuentros culturales.

Con definición de temáticas guía se codificó y sistematizó información sobre:

- Sabedores locales.

- Generación y género de los sabedores.

- Conocimiento del entorno local.

- Conocimientos sobre el suelo-selección, clasificación, indicadores.

- Actividades productivas tradicionales.

- Se indagó sobre el manejo de semillas.

- Consecución de las semillas.

- Técnicas de siembra.

- Especies principales en los cultivos o fincas.

- Prácticas tradicionales aplicadas a estas especies.

- Prácticas perdidas.

- Listado de especies más utilizadas.

- Forma de uso y parte de la planta que se usa.

- Especies de valor alimenticio y cultural perdidas total o parcialmente.

- Importancia social, cultural y alimenticia de las especies perdidas.

- Posibles causas de estas pérdidas.

- Especies útiles-silvestres y/o cultivadas.

- Especies asociadas en los cultivos.

- Uso de las especies útiles.

- Interés social.

- Manejo del territorio.

- Manejo de las especies de fauna y flora.

\section{Resultados}

Dos estrategias de manejo de ecosistemas. Los pueblos asentados en el Pacífico tienen muchas aproximaciones al territorio región del Pacífico y en particular a sus ecosistemas específicos; es diferente el manejo que ejerce una población asentada en ecosistemas costeros con manglares o con riscales a la que hace una asentada a orillas de una gran cuenca como la del Atrato, el San Juan, el Mira, el Saija u otra de las tantas del Pacífico o a una asentada en el pie de monte; también son diferentes los manejos que se hacen si la vocación productiva del área es minera, maderera o pesquera. Sin embargo, existen elementos comunes acorde con las culturas desarrolladas por los pueblos afropacífico o aborígenes y es a partir de estos elementos que se fija la atención en este artículo.

Respaldos. Antes de conformarse los conglomerados actuales, los pueblos asentados en el Pacífico tanto afros como aborígenes tuvieron asentamientos dispersos por familias que ubicaban sus viviendas a orillas de ríos y quebradas. Esta presencia caracterizó una manera común de manejar los territorios con un frente y un fondo o respaldo. A diferencia de las poblaciones campesinas del resto del país que organizan su territorio con criterios prediales de polígonos definidos en fincas, conárea de superficie medida con precisión y expresadas en unidades de superficie, metros, hectáreas, kilómetros cuadrados o cuarterones, fanegadas, etc., los pueblos afro reconocen con otros criterios su territorio.

Las señales de límites del respaldo son solo el frente delimitado por mojones naturales, quebradas, árboles insignias, cerros, montículos o divisorias de agua y un fondo que no tiene límites definidos sino líneas imaginarias y flexibles que se entrelazan con territorio de dominio de otras familias. La flexibilidad no es expresada solamente 


\section{Bioetnia Volumen 12, 2015}

en los límites, también en el uso, tanto del aprovechamiento de los recursos como de la posibilidad del establecimiento de una parcela o colino por otra familia, factible bajo algunos criterios de comunicación. El respaldo equivale al "monte" en la acepción que le describe Restrepo (1996), el cual se puede diferenciar en monte bravo o monte biche ordenado horizontalmente a partir de un eje adentro/fuera, es decir, desde al río hasta el monte, donde el primero representa lo más afuera y el segundo lo más adentro. Esta representación se relaciona con los movimientos de personas u objetos; una persona se dirige hacia adentro si va del río al monte o se sacan hacia afuera recursos maderables o presas de caza desde el monte hacia fuera. Igualmente estas categorías se relacionan con género, lo masculino está conectado con lo de adentro mientras lo femenino con lo de afuera. Los hombres ejercen la mayoría de sus actividades en el monte mientras que la mujer lo hace en el río o la vivienda con los niños. En este sentido el monte se asocia con lo masculino mientras que el río y la vivienda con lo femenino.

El monte es asociado con lo peligroso no solo por la propensión a los accidentes sino también porque allí habitan seres tangibles o imaginarios que pueden hacer daño o causar enfermedades o la muerte como una araña, una conga, una culebra, un tigre o un nusí, un dopacadde o un guangano. El respaldo tiene una función de estrategia amigable a la naturaleza en cuanto permite la existencia de un cuerpo boscoso en donde se conservan los ecosistemas con todos los seres que le habitan, vegetales y animales, macroscópicos y microscópicos; en el respaldo se mantienen valores culturales tradicionales que resuelven necesidades cotidianas y valores de opción futura para la vida de la comunidad, recursos aprovechables para la medicina natural, para la seguridad alimentaria, para la solución de necesidades infraestructurales, etc. En el sistema tradicional Embera o en el afro no es concebible la ampliación de cultivos que lleguen a suprimir los respaldos; en otras palabras, el sistema económico se centra en la vida en general y no en el crecimiento de la producción de bienes y servicios; es un concepto cercano a la biomimesis o imitación de la economía humana a la economía natural de los ecosistemas planteada por Mumford (1956), quien propuso la ideología orgánica, coherente con la economía centrada en la vida.

\section{Encierros}

Constituyen una estrategia amigable a la naturaleza que si bien se origina en la cosmovisión Embera es acogida como referente del ordenamiento territorial entre las comunidades negras. El encierro es un concepto espiritual que en ocasiones implica áreas territoriales; se encierran los espíritus o jais dentro de una ceremonia para controlar un malestar de la salud de un individuo o una distorsión en el bienestar de una comunidad, por ejemplo, "el jaibaná, en las ceremonias siempre trabaja en alianza con los jais. Al iniciar el ritual, los llama, utilizando para ello en ocasiones un caracol marino. Los jais se movilizan en barcos hasta llegar a la casa del jaibaná donde se incorporan a la ceremonia, realizando el trabajo que se pretenda llevar a cabo, ya sea la curación de una persona o el encierro de algún monstruo que está atentando contra la vida de los habitantes del caserío, en un determinado lugar" (Hernández, 2005). Son diferentes los objetivos de rituales en los que se practican los encierros de espíritus, "se siguen realizando rituales como el faruka, jaibanismo, curación, sembrar, limpiar el agua, conservar la tierra, fortalecer los pescados, encierro de algún espíritu, hacer sanación de territorios, de enfermos, quitafui" (ACIR y Ministerio del Interior, 2012)

Para la práctica de los encierros se utilizan factores externos o estimulantes que lleven a mejorar las condiciones corporales para facilitar la relación con seres que se expresan en forma diferente a la de los humanos. 
...de otro modo, uno de los objetivos de la toma de yagé y de borrachero es la estimulación sensorial, dado que con ello se busca agudizar los cinco sentidos como paso previo y obligatorio para poder entrar en contacto con los seres del mundo inmaterial y poder ejercer todas las funciones chamánicas, como es: ver el mal y contrarrestarlo, encontrar personas o cosas pérdidas o encontrar y liberar los animales de sus encierros, entre otras actividades" (Rubiano, 2010).

Los encierros demarcan áreas territoriales específicas donde se debe expresar un tipo de comportamiento particular por parte de las personas que habitan el territorio; ordinariamente las partes altas, las lagunas ubicadas en sitios apartados, los bosques con características particulares de luminosidad, especies forestales, sonidos de paisaje, ensenadas o pozos oscuros o correntosos, con remolinos, peñascos y cuevas, entre otros, son considerados "sagrados". Los cerros y páramos denominadas en Embera "jaikatuma" o cerro de jais; ejemplos de ello son "usakira", o cara de perro, en la parte alta del río Murrí, límites entre Antioquia y Chocó, municipios de Pavarandó en Antioquia y Carmen del Darién en el Chocó y Janano y Jananito en el municipio de Nuquí, corregimiento de Arusí.

Los sitios sagrados o lugares de encierro tienen limitado el ingreso o realización de actividades y por las características sagradas que les revisten son respetadas en forma masiva; por tradición oral toda la población conoce que en estos lugares existen fieras o entes sobrenaturales conocidos con las denominaciones de Nusí, Dopacadde, Riviel, Tulivieja, entre otros y que actúan sobre las personas haciéndolas perder la orientación en los caminos o creando estados de locura, encantamiento o produciendo directamente la muerte.

Respaldos y encierros funcionan social y territorialmente como estrategias de conservación en la medida en que se asocian con la reproducción, refugio o circulación de fauna de caza, distribución de especies vegetales e insectos usados en las terapias de salud tradicional, reproducción y crecimiento de peces. Son lugares en los que se limita la intervención antrópica a aprovechamiento ocasional de algunas especies, actividad que la hacen exclusivamente los Jaibanás o Tongueros.

\section{Prácticas tradicionales amigables con el ambiente en el modelo de producción agrícola comunitario}

Selección de suelos. La selección del terreno se realiza teniendo en cuenta el color y la textura del suelo; este debe ser preferiblemente café oscuro de una textura semihúmeda. La presencia de indicadores de flora y fauna advierten las buenas condiciones del terreno para la plantación del cultivo de plátano, árboles de lechero (Sapium stylare) (por la rápida descomposición de sus hojas), palmazancona (Syagrus sancona) y meme (Wettinia quinaria), el guamo (Inga spp), guácimo (Guazuma ulmifolia) y pringamosa (Urtica dioica); animales como el pavón (Crax alberti), la catanica (Amazona autumnalis), perica (Psittacara holochlorus) y chau chau (Psarocolius decumanus). Para la siembra del maíz, se prefieren terrenos inclinados, que cuenten con la presencia de plantas indicadoras como la cañabrava ( $G y$ nerium sagittatum), yarumo (Cecropia peltata), lechero (Sapium stylare), guabo (Inga sp), iraca (Carludovica palmata), balso (Ochroma pyramidale) y animales como chapul (Anacridium aegyptium), ardilla (Sciurus vulgaris) y mono maicero (Cebud Apella). El suelo para sembrar arroz depende del tipo de semilla; si es secano o de agua, estos últimos se identifican por la presencia de animales como la guacharaca (Ortalis ruficauda), el pato silvestre (Anas platyrhynchos), la chicamia (Basiliscus Plumifrons) y chimbilaco (Desmodus rotundus) y plantas como la hoja de garza (Anthurium acaule), platanilla (Heliconia bihai), iraca (Carludovica palmata), moja o 


\section{Bioetnia Volumen 12, 2015}

monja boba (Lycaste virginalis), balso (Ochroma pyramidale) y el higuerón (Ficus luschnathiana).

El conocimiento para la selección de suelos tiene gradaciones; existen elementos generales que son comunes a todos los iniciados en la agricultura, pero existen sabios tradicionales que conocen a profundidad el arte de elegir un suelo apto para el desarrollo de cultivos, pues no todo suelo sirve para sembrar especies y cada suelo tiene su aptitud para el mayor desarrollo de especies, particularmente aquellas de mayor valor de uso. Son personas mayores y cuyo énfasis productivo está en la agricultura quienes tanto en las comunidades embera como negras poseen esta misión; sin embargo, no es extraño encontrar personas jóvenes que por vocación ya son conocedoras del arte de la selección de suelos.

Existen suelo que tienen vocación para cultivos, los valles de quebradas y ríos tienen particularmente esta características, sin embargo, según versión de los conocedores, se cansan y deben dejarse recuperar sin cultivos durante un tiempo mayor de cinco años con el objeto de que tengan nuevamente las condiciones para ser plantados.

Hace parte de la selección de los suelos a ser utilizados en la agricultura el que estos no sean contiguos, regularmente son rodeados de monte bravo con un frente en una quebrada o río, por donde se facilita el transporte de los productos. Esta práctica de selección determina el que no se conciba dentro del sistema productivo la ampliación de la frontera agrícola y si a esto se le suma el hecho de que el uso es temporal, en ciclos que oscilan entre 5 y 7 años, se prefigura un continuo de bosque que garantiza una dinámica inagotable de las especies nativas del entorno.

Otro factor importante de la selección es el área que se dedica a ser cultivada. El IIAP investigó este tema en tres comunidades Embera pusabidara del municipio de Nuquí encontrando los siguientes promedios: Bocas de Jagua, río Chorí, se midieron 22 colinos o parcelas y se encontró un área promedio de $0.834 \mathrm{ha}$, es decir, $8.340 \mathrm{~m}^{2}$; en la comunidad de Yucal, río Panguí se midieron 23 colinos o parcelas y se encontró un promedio de 1.281 ha es decir, $12.810 \mathrm{~m}^{2}$; en la comunidad de Nuquí Arriba, río Nuquí se midieron 21 colinos o parcelas y se encontró un promedio 1.187 ha es decir, $11.870 \mathrm{~m}^{2}$. En síntesis el promedio del área usada con cultivos asociados entre los Embera pusabidara del Golfo de Tribugá es de 0.822 ha $\left(8.220 \mathrm{~m}^{2}\right)$, un poco menos de una ha por área. Vale aclarar que cada familia tiene entre dos y tres parcelas por lo que se podría concluir que el área usada en cultivos asociados por las familias Embera pusabidara del Golfo de Tribugá en el año 2013 era de alrededor de 2.5 ha. Igualmente se indagó en tres comunidades negras encontrando los siguientes promedios: Partadó, se midieron 20 colinos o parcelas y se encontró un promedio de 1.094 ha $\left(10.940 \mathrm{~m}^{2}\right)$. En la comunidad de Joví se midieron 18 colinos o parcelas y se encontró un promedio de 1.391 ha $\left(13.910 \mathrm{~m}^{2}\right)$ y en la comunidad de Termales se midieron 19 colinos o parcelas y se encontró un promedio de 1.101 ha $\left(11.010 \mathrm{~m}^{2}\right)$. En síntesis el área usada en cultivos asociados por las familias de comunidades negras en el Golfo de Tribugá en el año 2013 era de alrededor de 1.195 ha $\left(11.950 \mathrm{~m}^{2}\right)$ por área. También entre las comunidades negras es usual que cada familia tenga un promedio de 3 colinos cultivados, por lo que el área usada para cultivos asociados por familia es similar al de los Embera pusabidara, es decir, 3.5 ha.

La selección se realiza en áreas conocidas por sus características: monte bravo o bosque primario: distinguen diferentes zonas: el changual o ciénaga que es terreno húmedo localizado en un monte bajo. El monte biche, o bosques de barbecho: se ubica en zonas donde se renuevan los cultivos. Es una siembra abandonada recientemente. El monte alzado o bosques en regeneración: es un rastrojo viejo en donde hay árboles grandes, generalmente de 10 a 15 años de edad.

Los colinos: se le llama colino a la asociación de especies maderables, frutales y silvestres 
útiles en un área con más de 500 plantas. En las comunidades negras se presenta la particularidad de llamar el área de siembra, teniendo en cuenta el cultivo principal sembrado; se caracteriza por el tamaño, la variedad de especies y el uso que se le da; y de esa manera puede ser una finca, un platanal, un bananal o una mejora.

Platanal, bananal o popochal: son aquellos sembrados que presentan como cultivo principal el plátano, el banano o el popocho, asociados con frutales, especies silvestres útiles y maderables.

Mejora: se le considera mejora a asociaciones de especies maderables, frutales y silvestres útiles en un área con más de 500 plantas que tienen entre 30 y 40 años.

Preparación de suelos. Para la preparación del terreno se procura utilizar el mínimo de labores en el suelo evitando la compactación de este y el volcamiento de las plantas; se encuentra entre los sembradores quienes prefieren no realizar ninguna actividad para la preparación del terreno, simplemente rozan y siembran sin socolar ni tumbar. Para sembrar socolan el terreno y cinco días después se siembra, luego se tumba.

La preparación de los suelos tiene variedades de acuerdo con la especie a sembrar; para el maíz, el cual no se siembra, sino que se riega al voleo, se inicia con la socola quitando los arbustos y lianas para permitir movilidad; seguidamente se riega el maíz y se concluye con tumba de los árboles dejando en pie aquellos de alto valor de uso y aquellos cuyo follaje permite la entrada suficiente de la luz solar al suelo; estas actividades las realizan preferiblemente en luna nueva. La siembra de cultivos asociados regularmente se hace en los mismos terrenos en donde se sembró el maíz, luego las primeras actividades de preparación de suelo son las mismas descritas, pero después de la tumba se dejan unos cinco días que caiga la hoja de las ramas y se hace una repica de ramas para permitir llegar hasta el suelo y hoyar a distancia aproximada de tres metros, ubicando los huecos en donde lo permite el terreno, sin alineamiento pero con certeza de las posibilidades de desarrollo de una buena planta y en las condiciones que posteriormente se facilite el chapeo o mantenimiento y la cosecha. Un poco diverso es la preparación de suelos para la siembra del arroz, único cultivo limpio que se realiza entre las prácticas agrícolas de emberas y negros, sea secano o de zonas inundables, se socola el monte, se tumba, se deja podrir la vegetación aproximadamente 15 días y luego se quema, donde el clima lo permite o se hace una repica y recolección de chamizas dejando el suelo expuesto al sol, en donde se regará la semilla de arroz; esta actividad se hace preferiblemente en luna llena para evitar el crecimiento (puya) de otras especies.

En general la preparación del suelo sigue una regla distintiva en la región que permite conservar las propiedades de fertilidad del suelo, marcada por la secuencia de socola, tumba, repica y pudre. La forma de hacer la tumba dejando árboles de diferentes doseles permite que haya conectividad entre la matriz de monte prístino o bravo y el área cultivada, por donde circula avifauna, insectos y las diferentes especies de fauna con distribución en la zona, ejerciendo sus funciones ecológicas de contribución en la descomposición de materia orgánica y distribución de semillas. La presencia de ramas y follaje sobre el suelo amortigua la erosión del suelo, protegiendo el horizonte fértil de las fuertes escorrentías producidas por la alta pluviosidad del lugar.

La preparación del suelo entre los embera es precedida por un ritual que se asocia con la "minga", la cual tiene una duración de varios días, iniciada con la preparación de la chicha y la convocatoria a las familias cercanas por proximidad física o por parentesco a participar del evento. El culmen de la minga es una especie de ritual en el que la comunidad hace una petición de permiso a la naturaleza para intervenirla; en este ritual el grano de maíz transformado en chicha se convierte en animador de los preparadores del suelo y es el primero en ser "regado" para que germine y a 


\section{Bioetnia Volumen 12, 2015}

la vez que ofrece alimento a las familias, aporta materia orgánica al suelo para acondicionarlo en la reposición de la cobertura prelevada.

Siembra de especies asociadas. Es una práctica ancestral que tiene regularmente una musácea como especie principal y determina el nombre del colino, un platanal, un bananal, un primitival, un popochal; quiere decir que el área tiene como cultivo principal el plátano hartón, el banano o el primitivo. La especie principal se asocia con diversas especies de distinto uso, alimenticias (tubérculos y frutales); medicinales, (raíces, tallos y follaje); maderables (Tabla 1).

Los monocultivos y cultivos limpios no son usuales, salvo el caso del arroz que se siembra en pequeñas áreas de diques y zonas inundables. Esta práctica además de ser una táctica para la defensa del desarrollo de plagas y enfermedades por la alelopatía, es una estrategia de mantenimiento de paisaje; cuando se miran los bosques desde el aire da la impresión de no existir intervención antrópica pues la selva se observa en continuo, porque las copas de la vegetación son similares en el bosque como en los cultivos asociados.

La siembra de especies asociadas se inicia por la selección de la semilla; cien (100) plántulas de cualquier musácea equivale a "una libra" de semillas. No se acostumbra tener almácigos para la conservación de las semillas; los mismos cultivos son fuente de semillas y algunas gramíneas se conservan en manojos protegidos de insectos a través de la exposición al humo y la mezcla con cenizas. La búsqueda de la semilla es también un motivo de encuentro entre familias o comunidades que intercambian semillas.

La libra es la unidad mínima e indica la medida del terreno a ser sembrado; lo normal es que ante la pregunta sobre el área plantada se responda: "tengo libra y media de banano sembrada". No se usan medidas de superficie convencionales como hectáreas, cabuya o fanegada. Traducir esta medida por semillas a una medida de superficie no

Tabla 1. Especies comúnmente asociadas con el cultivo de plátano hartón

\begin{tabular}{llll}
\hline Frutales & Artesanales & Maderables & Medicinales \\
\hline Borojó & Bejuco potré & Níspero & Venadillo \\
Aguacate & Iraca & Choiba & Costeña \\
Almirajó & Mil pesos & Cedro macho & Cordoncillo \\
Chirimoya & Zancona & Jigua & Yerba buena \\
Guayaba & Meme & Espave & Amaranto \\
Limón & Cuchilleja & Guina & Violeta \\
Chontaduro & Táparo & Carbonero & Guaco \\
Papaya & Tagua & Granadillo & Tortugo \\
Banano & Werregue & Aceite & Cargamanto \\
Popocho & Chocolatillo & Carrá & Amargosa \\
Filipita & Kipará & Pantano & Debaratadora \\
Bacao & Imbica & Sande & Sauco \\
Caña & Achiote & Balso & Poleo \\
Guanábana & Manchare & Pacocito & Galbe \\
Guama & Kiddabe & Tachuelo & Paico \\
Naranja & & Espavé & Santamaría \\
Mandarina & & Guadua & Contragavilana \\
Lulo & & Truntago & Pringamosa \\
\hline
\end{tabular}


es tan sencillo pues existe la práctica de sembrar "flojo" y la de sembrar "apretado"; el primero ocupa mayor área mientras que el segundo menos. Sin embargo, existen aproximaciones; se calcula que a una distancia de tres metros por plántula, en una hectárea se siembran siete libras de plátano, lo que equivale a 700 plántulas. Los hoyos se hacen con medidas también aproximadas de 30x30x30; sin embargo, es normal que el hoyo se haga con las medidas aproximadas de la plántula.

Si bien poco se mencionan las especies que se asocian con el cultivo considerado principal, estas juegan un rol importante tanto en la seguridad alimentaria como en las intenciones de producción de los cultivadores. El número de plántulas introducidas en un colino demuestra el interés en el uso de la misma; sin embargo, es hábito "dejar" en el terreno especies silvestres a pesar de no tener intención expresa de usarlas, son un valor de opción futura ante una eventualidad de salud o decisión de construir un gallinero, una porqueriza o una nueva vivienda. Acorde al conocimiento tradicional enfatizado por el dueño del cultivo también se deja mayor número de especie de interés; si se trata de un médico tradicional o alguien que conoce de maderas son estas especies usadas en medicina o la construcción las que dominan después del cultivo principal.

Mantenimiento de cultivos. Tres meses después de la siembra, se platean las plantas y durante su proceso de crecimiento se le realizan dos limpiezas (manejo de malezas), y antes del "corte" o cosecha, se apuntalan; para prevenir enfermedades se remueven las hojas no funcionales del tallo y aquellas que están rosando o encima del racimo.

Para la consecución de semilla se realiza el deshije dentro del cultivo, se seleccionan los colinos con mayor vigor; se realizan varios deshijes en una cosecha, el primero es aproximadamente entre los 5 y 7 meses de edad de las plantas, luego en cada limpieza que se le hace al cultivo, se eliminan los rebrotes cada 7 a 8 semanas.

Este cultivo se sembraba en tiempo de vera- no, cubría entre los meses de enero a abril; era la época apropiada para la siembra del plátano ya que por las pocas lluvias se facilitaba la preparación del terreno. Actualmente se siembra en cualquier época del año; solo se tiene en cuenta las fases de la luna; que para este cultivo es en luna menguante.

Existen prácticas de mantenimiento diferenciadas por cultivo como:

Manejo del cultivo de maíz. A las plántulas durante la etapa de crecimiento se les realiza monitoreo cada mes. Cuando estas lo requieren se les realiza deshierbe; treinta días después si el cultivo lo requiere se le hace aporque a las plantas. La cosecha, dependiendo la variedad, se realiza a los cuatro meses para maíz y choclo y a los cinco o seis ya está seco o maduro. Antiguamente se regaba el maíz en seis manos o tandas, 50 veces siendo igual a 300 mazorcas llamadas almud grande. Actualmente se riegan cuatro manos o tandas 64 veces equivalentes a 256 mazorcas o almud pequeño.

Manejo del cultivo del arroz. Antes de cumplir el mes de sembrada la semilla, se les realiza una actividad llamada "mateo", que consiste en retirar plantas de los hoyos que tengan más de tres plántulas y resembrarlas en otro hoyo, con el objetivo de evitar competencia entre ellos y proporcionarles un buen desarrollo. Después de esta actividad se les realiza deshierbe cada dos meses. Se cosecha en un tiempo aproximado de 5 a 6 meses, en los cuales se les realiza limpieza dos veces durante su crecimiento.

Descanso del suelo o de áreas de siembra. Las comunidades practican una producción migratoria que consiste en la limpieza de pequeñas áreas (colinos), no mayores a las dos hectáreas, para la siembra, dejándola descansar luego de varias cosechas, por un tiempo determinado, pasando a otro espacio, rotando hasta llegar al terreno inicial ya convertido en barbecho (de 10 a 20 años). Antiguamente los tiempos de aprovechamiento de un área eran regulares, siete cosechas de plátano, 


\section{Bioetnia Volumen 12, 2015}

es decir alrededor de siete años; actualmente este período ha disminuido debido al agotamiento de la productividad de los cultivos principales, porque el plátano debido a factores externos como enfermedades tipo sigatoka negra o amarilla o la presencia del covatierra (Orthogeomys $s p$ ) acelera el deterioro de las plantaciones o de factores internos, pues las variedades van perdiendo las condiciones genéticas y ello también hace más cortos los períodos de producción.

Los escenarios por los que giran los cultivos asociados tienen denominaciones particulares en el Pacífico:

- Monte biche o rastrojo: se le llama así al área de siembra con un descanso de aproximadamente tres años; se caracteriza por tener una vegetación joven (de tallo delgado, fácil de rozar).

- Monte alzado: es un área de siembra con un descanso de siete años, se caracteriza por tener una vegetación con un diámetro mayor a $10 \mathrm{~cm}$.

- Monte jecho o bravo: es el área con más de 10 años de descanso.

Entre los Embera se tienen rotaciones totales en quebradas completas; todas las familias de una comunidad se desplazan suspendiendo todas las intervenciones antrópicas, incluida la de las viviendas. Esta práctica es asociada con guerras chamánicas entre jaibanás, quienes miden poderes y cuando uno de ellos no puede proteger a su comunidad y se presentan signos como la muerte de miembros de la comunidad, particularmente niños, ordena el desplazamiento de toda la comunidad bajo su protección a una comunidad distante del otro jaibaná con el objeto de evitar percibir el daño de sus jais. Esta práctica coincide regularmente con el agotamiento de las condiciones ecológicas del medio disminuyendo la oferta ambiental ligada con la seguridad alimentaria y el agotamiento de la fertilidad del suelo afectando la productividad de cultivos. Esta práctica configura un tipo de rotación que permite que toda la región restaure sus dinámicas ecosistémicas en forma pasiva repoblando la biodiversidad y en general con fauna, incluida la macroscópica y microscópica, y la flora.

\section{Discusión}

¿Qué tanto se conservan las estrategias y prácticas productivas tradicionales expuestas en este artículo?

Las comunidades conservan costumbres y métodos de siembras tradicionales; en los resultados de esta investigación se puede apreciar que siguen vigentes tanto estrategias como prácticas tradicionales aplicadas sea al manejo de territorio como a cultivos principales. Sin embargo, hay cambios culturales y cambios en las condiciones ecológicas del territorio que llevan a deteriorar la efectividad de la conservación generada en estas. La sustitución de productos asociados con el sistema alimentario y productivo, el interés por la adquisición de equipos y herramientas, la apropiación de prácticas externas, han llevado en forma paulatina a deteriorar el sistema productivo y ambas etnias necesitan con urgencia fortalecimiento en sus actividades productivas tradicionales, recuperar especies de importancias de uso alimenticias, maderables y medicinales. El sistema educativo y el de salud está acelerando la pérdida de tradiciones como las enunciadas en las nuevas generaciones, cuyos miembros en forma masiva son expulsados de su territorio en búsqueda de oportunidades sean de perfeccionamiento de sus estudios, laborales, o de atención en salud. Las culturas son dinámicas y apropian cambios que son irreversibles, sin embargo, también las culturas mantienen sus raíces culturales y defienden tradiciones, particularmente aquellas que le brindan identidad y bienestar material y espiritual. Las dos etnias que mantienen estas estrategias y prácticas les reivindican como elementos de identidad y orgullo y es por ello que luchan por mantenerlas. 


\section{¿Quétan eficientes son las prácticas produc- tivas en la garantía de la seguridad alimentaria?}

El plátano, el maíz y el arroz son tres productos que orientan la vigencia de las prácticas productivas y están asociadas con las estrategias en la medida en que son encierros y respaldos los soportes de la continuidad de la rotación y por ende el mantenimiento de la dinámica del sistema: la población actual por comunidad es de 200 a 400 habitantes aproximadamente y en la cabecera municipal es de 3.252 habitantes (Alcaldía de Nuquí, 2012), la producción de plátano anual por hectárea es de aproximadamente 70 raciones; una ración tiene 64 plátanos (25 kilos aproximadamente), o sea que una hectárea anual está produciendo 4.480 plátanos. De ser así en el caso de las musáceas, no se está presentando un déficit de producción porque si a esto le sumamos la recuperación de las variedades perdidas y el fortalecimiento de los cultivos con estas, se obtiene un mejor resultado. Sin embargo, se acusa un déficit de semilla en buenas condiciones, la cual se debe recuperar de comunidades retiradas como las asentadas en el Baudó. El proyecto mencionado impulsó la recuperación de dinámicas de intercambio de semillas; sin embargo, es necesario darle continuidad a estas actividades hasta reestablecerlas. La producción de maíz es de 30 a 40 sacos por hectárea (14.5 kilos); en las cuatro comunidades indígenas participantes se están cultivando actualmente 20 hectáreas de maíz, cosechando anualmente entre 600 y 800 sacos de maíz; por lo tanto hay un déficit, se requiere un fortalecimiento en la producción. Para esta recuperación se debe tener en cuenta tanto las variedades como la cantidad de semillas, las mazorcas de maíz, especialmente el denominado chococito son cada vez más pequeñas y disminuye no solamente la cantidad de producción sino el entusiasmo de los cultivadores que ven sus esfuerzos perdidos. Al recuperarse las variedades que se han perdido, se fortalecen los sembrados y se diversifica la producción, logrando con esto equilibrar la oferta y la demanda de maíz. Se ve la necesidad de ampliar los cultivos, se cuenta con las tierras y la mano de obra. La producción de arroz es de 60 bultos por hectárea (un bulto pesa 24 libras); en las comunidades participantes se tienen sembradas aproximadamente 9 hectáreas, resultando una producción anual de 1.080 bultos de arroz. Este no alcanza para abastecer la demanda de las familias; es necesario impulsar el cultivo con la recuperación de las variedades naturalizadas al medio con reconocido resultado productivo y altos niveles de apropiación de sus dinámicas de manejo por parte de las familias.

¿Qué tanto riesgo de desaparición pueden tener las estrategias y prácticas?

El riesgo que tienen las prácticas productivas a desaparecer, depende de la efectividad que se tenga para recuperar una buena cantidad de especies nativas; con esto se retoma no solo actividades relacionadas con la producción sino también sociales y culturales. Junto con muchas especies se han desaparecido platos típicos, fiestas culturales, encuentros y demás expresiones culturales necesarias para la conservación de la identidad cultural y el arraigo territorial. Es necesario un esfuerzo por mantener la esencia de las tradiciones así sea con variaciones normales en su vivencia, las cuales se ven forzadas por los nuevos imaginarios que entran a formar parte de la vida social y política de las comunidades como son los límites territoriales, los reglamentos de manejo de recursos, las nuevas estructuras organizativas, entre otros generados en el nuevo fuero legal.

\section{Literatura citada}

Alcaldía Municipal de Nuquí. 2012. Plan de Desarrollo Desarrollo con Equidad Social. Nuquí: Alcaldía de Nuquí; 116 pp. URL disponible en: http://cdim.esap. edu.co/BancoMedios/Documentos\%20PDF/nuqu\%C3\%ACchocopd2012-2015.pdf

Asociación de Cabildos Indígenas de Risaralda (ACIR), Ministerio del Interior. 2012. Plan salvaguarda de los Emberas Chami del departamento de Risaralda. Pereira: Ministerio del Interior; 272 pp. URL dispo- 


\section{Bioetnia Volumen 12, 2015}

nible en: http://www.mininterior.gov.co/sites/default/ files/p.s embera chami risaralda.pdf

Fals Borda O. 1981. La ciencia y el pueblo en investigación participativa y praxis rural. Lima: Mosca Azul Editores; 56 pp.

Hernández C. 2005. Emberas: Territorio y biodiversidad. Estrategias de control en escenarios de conflicto. Bogotá: Programa Semillas y Fundación Swissaid de Colombia; 11 pp. URL disponible en: https://bioculturalblog.files.wordpress.com/2013/09/lectura-1-pensamiento-sobre-el-territorio-embera.pdf

Instituto de Investigaciones Ambientales del Pacífico (IIAP). 2012. Diagnóstico, caracterización de prácticas tradicionales, identificación de especies que brindan bienes y servicios, descripción de procesos y manejos productivos de las actividades productivas realizadas por las familias indígenas Emberas y afrocolombianas del golfo de Tribugá. Informe técnico. Quibdó: IIAP; $180 \mathrm{pp}$.

Mumford L. 1956. Historia natural de la urbanización. Chicago: Instituto Juan de Herrera: 156 pp. URL disponible en: http://habitat.aq.upm.es/boletin/n21/ almum.html

Ortiz M, Borjas B. 2008. La investigación acción participativa: aporte de Fals Borda a la educación popular. Espacio Abierto. 17 (4): 615-27. URL disponible en: http://www.redalyc.org/articulo.oa?id=12217404

Restrepo E. 1996. Cultura y biodiversidad en Pacífico. ¿Desarrollo o diversidad? Pedrosa AE (ed.) Bogotá: CEREC-ECOFONDO.

Rubiano J. 2010. Sobre el trance, el éxtasis y los estados alternos de conciencia en el chamanismo de tierras bajas, una visión desde los Embera-Chami y Kofan del Putumayo. Bol Antropol. 24 (41): 207-22. 